\title{
Totally videoscopic bilateral, simultaneous lumbar sympathectomy: original modification - preliminary report
}

\author{
Tomasz Stefaniak ${ }^{1}$, Dariusz Łaski ${ }^{1}$, Łukasz Kaska ${ }^{1}$, Łukasz Znaniecki ${ }^{2}$, Jacek Krajewski ${ }^{1}$, Monika Proczko-Markuszewska' ${ }^{1}$, \\ Jarosław Kobiela ${ }^{1}$, Andrzej J. Łachiński ${ }^{1}$, Zbigniew Śledziński ${ }^{1}$ \\ 1Department of General, Endocrine and Transplant Surgery, Medical University of Gdańsk, Gdańsk, Poland \\ 2Department of Vascular and Cardiac Surgery, Medical University of Gdańsk, Gdańsk, Poland
}

Videosurgery and other miniinvasive techniques 2010; 5 (1): 7-13

DOI: 10.5114/wiitm.2010.13600

\begin{abstract}
Introduction: Lumbar sympathectomy seems to be technically a much more demanding procedure than thoracic sympathectomy. Nevertheless, some patients require this particular procedure. In our centre, the operation is performed no sooner than 12 months after initial thoracic sympathectomy as a simultaneous bilateral retro-peritoneoscopic procedure. Aim: To evaluate early effectiveness of totally videoretroperitoneoscopic lumbar sympathectomy from a posterior approach.

Material and methods: Between June 2008 and June 2009, there were 12 patients operated on for primary plantar hyperhidrosis in the Department of General, Endocrine and Transplant Surgery, Medical University of Gdansk, Poland. A bilateral procedure was performed in 6 patients, and in 6 other cases (initial ones) the procedure had to be split due to too slow progress of the procedure (learning curve).

Results: Mean operation time was $92.5 \pm 27.16 \mathrm{~min}$ (for 6 bilateral procedures) and $84 \pm 20.17 \mathrm{~min}$ (for the initial 12 unilateral procedures). There was no postoperative mortality. Morbidity involved post-sympathectomy syndrome presenting as moderate burning pain in the buttocks and thighs up to 4 weeks postoperatively. Postoperative stay was 1 day in 7 cases and 2 days in 3 cases (due to long train travel awaiting the patient on his/her way home). In the majority of patients, early postoperative results were very good, expressed by both the subjective opinion of the patient and gravimetric results. In one case dryness of the feet was so severe that the patient had to consult a dermatologist.

Conclusions: We believe that videoretroperitoneoscopic lumbar sympathectomy from a posterior approach is a good method of treatment for primary hyperhidrosis with plantar symptoms, but should be reserved for surgeons experienced in laparoscopic and retroperitoneoscopic surgery.
\end{abstract}

Key words: lumbar, sympathectomy, hyperhidrosis, gravimetry.

\section{Introduction}

Lumbar sympathectomy was performed for the first time by Julio Diez in 1924 in Buenos Aires [1]. Royle in Australia and Adson in the USA performed it at the same time (1925) [2]. Diez, Royle and Adson offered this procedure for critical lower limb ischaemia
[1], Raynaud's disease [2] and experimentally in patients with spastic paralysis [3]. The benefit of lumbar sympathectomy can be explained in terms of counteraction of the vasoconstriction from the sympathetic system and elimination of nociceptive impulsation, especially in skin blood vessels [4]. 
Thanks to development of modern revascularization techniques, the significance of this procedure receded in favour of prosthesis placement and endovascular treatment $[5,6]$. Lumbar sympathectomy for vascular indications is a method of second or third choice, when reperfusion is not possible with other methods or when the patient does not consent to the offered procedure $[7,8]$.

Today, sympathectomy is tried for treatment of complex regional pain syndrome (CRPS) [9, 10], primary hyperhidrosis $(\mathrm{PHH})[11,12]$, Buerger's disease [13], Raynaud's syndrome [14, 15], chronic leg ulcer [16], frostbite [17], erection problems [18], and painful legs and moving toes syndrome [19].

Progress in laparoscopic surgery, advancement of available tools and increasing experience of surgeons in minimally invasive surgery create new opportunities for lumbar sympathectomy, which is not often done with a totally videoscopic technique. So far we have not found any publication in Polish literature on totally videoscopic lumbar sympathectomy, while there are only 26 in the mundane literature. Studies on posterior access were performed only experimentally [20,21]. In patients with vascular diseases cosmetic effects of surgery can be less significant, yet in patients with primary hyperhidrosis minimization of invasiveness of the procedure and concern for best cosmetic effects seem reasonable. Posterior access videoperitoneoscopic sympathectomy, which we propose, meets both criteria.

Primary hyperhidrosis is now the main indication for both lumbar and thoracic sympathectomies [22] The ailment is estimated to make up $84.3 \%$ of all indications for surgical sympathectomy [23]. This is easily understandable, since $1 \%$ of the population are affected by the illness [11]. Primary hyperhidrosis is a hereditary disease of unclear aetiology and pathomechanism [24]. Perspiration is a main symptom, with excretion of more than $40 \mathrm{mg}$ of sweat per minute, affecting mainly the palms and feet but also the face, armpits and abdomino-lumbar regions [12]. In spite of normal histological structure, sudoriferous glands overreact to sympathetic stimulation. Symptoms start in childhood, which added to little support from the family, insufficient knowledge of disease treatment among primary care physicians, ineffectiveness, short-lived action or side effects of available treatment methods (aluminium chloride, formaldehyde, iontophoresis, botulinus toxin) [25] - results in poorer quality of life [12]. Patients withdraw from social life. Hyperhidrosis makes many daily activities and jobs more difficult, and failure to obtain medical help in extreme disease manifestation leads to depression and suicide [12, 26].

In this respect, the operative technique which we propose below seems to be an optimal way of treatment for hyperhidrosis of the feet, and gives permanent improvement of life quality at the cost of relatively low operative risk and low complication rate.

\section{Material and methods \\ Patients}

Between July 2008 and July 2009, twelve patients with primary hyperhidrosis of the feet were treated in the Department of General, Endocrine and Transplant Surgery of the Medical University of Gdańsk. In one of the patients complex regional pain syndrome (CRPS) of lower limbs was an additional indication for surgery. The group of operated patients consisted of 10 women and 2 men aged $30 \pm 11$ years. Patients were qualified for surgery on anamnesis, gravimetry and physical examination aimed at exclusion of secondary causes of hyperhidrosis [12].

\section{Operative technique}

The procedure is performed under general anaesthesia, with the patient positioned on her/his abdomen. A 2-cm-long incision is made $10 \mathrm{~cm}$ laterally from the midline, at the level of $\mathrm{L} 3$. An operative space is created by pushing adjacent tissues away. Then, under guidance of a finger, two $5 \mathrm{~mm}$ trocars are placed $2 \mathrm{~cm}$ above and below the incision in the posterior axillary line. A $10 \mathrm{~mm}$ trocar is inserted through the primary incision (Figure 1). The retroperitoneal space is inflated with $\mathrm{CO}_{2}$ up to $22 \mathrm{mmHg}$. Once access to the retroperitoneal space is achieved, the lumbar vertebrae and sympathetic trunk are visualized along the lumbar muscle. The L3 sympathetic plexus is excised with a short fragment of the trunk above and below the plexus (Figure 2). The tools are removed and the skin is sutured. In bilateral procedures, the procedure is repeated on the contralateral side.

Assessment of the procedure included both standard variables (duration, intraoperative blood loss) and subjective evaluation of the following by the operating surgeon: surgical access, anatomical difficulties, subcutaneous bleeding, intra-abdominal bleeding, quality of patient's anaesthesia. Each variable was judged on a 1-10 interval scale. Then, the 


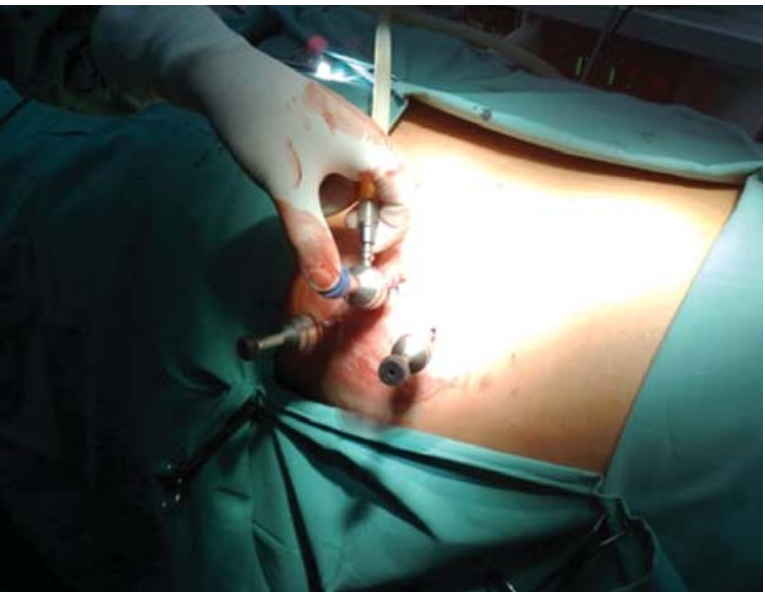

Figure 1. Trocar placement (patient positioned on the abdomen, right side)

results were weighed, averaged out and presented as the procedure difficulty index (with values from 0 to 1 ).

Disease staging was performed before, and 3 months after the surgery. Subjective assessment of general disease-attributable symptoms and extent of sweating in each body area was carried out by the patient on a visual analogue scale (VAS, 1-10). Moreover, objective measurement was accomplished with gravimetry, as described elsewhere [12].

\section{Results}

Twelve unilateral videoperitoneoscopic lumbar sympathectomies and 6 bilateral procedures were performed in the study population. In two patients after a unilateral procedure resolution of hyperhidrosis was incomplete (in one patient the procedure could not be completed due to technical failure of the inflator), and after another 2 simultaneous, bilateral procedures no improvement was noted. In 18 procedures, in which 24 sympathectomies were performed, incomplete resolution of hyperhidrosis occurred in 4 cases (17\% of all sympathectomies, Figure 3).

Mean operation time was $84 \pm 20.17 \mathrm{~min}$ in unilateral and $92.5 \pm 27.16 \mathrm{~min}$ in bilateral procedures. Surgeons assessed the unilateral procedure as an easy one: $1.7 / 10$. Bleeding from the subcutaneous tissue, retroperitoneal space and anaesthesia did not complicate the procedure - respectively 1.33 ; 1 ; $0.75 / 10$. The main difficulties during the procedure were caused by anatomical issues (mean 3.42/10) and by operative access (1.75/10). Simultaneous bilateral

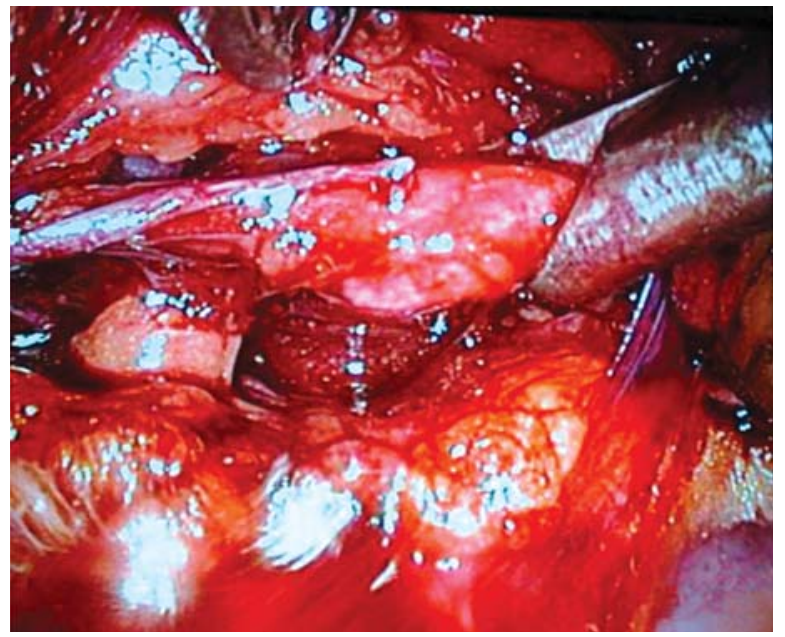

Figure 2. Isolated sympathetic L3 ganglion

procedure was assessed as relatively easy (2/10). Subcutaneous bleeding, intra-abdominal haemorrhage and anaesthesia created no problems in bilateral procedures (respectively, 1.5; 1; 1.33/10). Surgeons, as in the unilateral procedure, considered the anatomical situation (mean 3.33/10) and surgical access (2.67/10) the main obstacles during the procedure.

No perioperative mortality was noted. All patients presented with symptoms of post-sympathectomy syndrome: not too severe pain in the buttocks and thighs that resolved after 4 weeks on average. In these patients administration of a non-steroid antiinflammatory drug was effective. In 2 patients, however, resolution of symptoms was not complete and no therapeutic effect was observed in 1 more

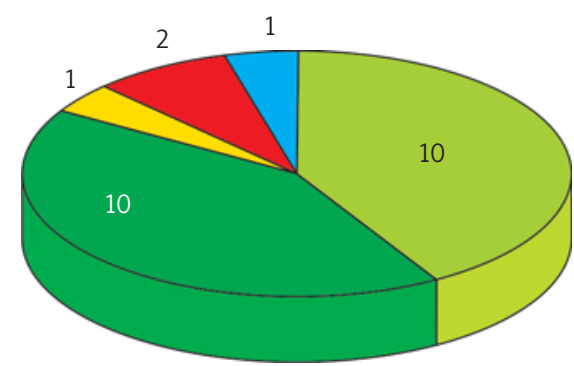

successful unilateral

successful bilateral

unsuccessful unilateral

unsuccessful bilateral

technical failure

Figure 3. Efficacy of performed lumbar sympathectomies 


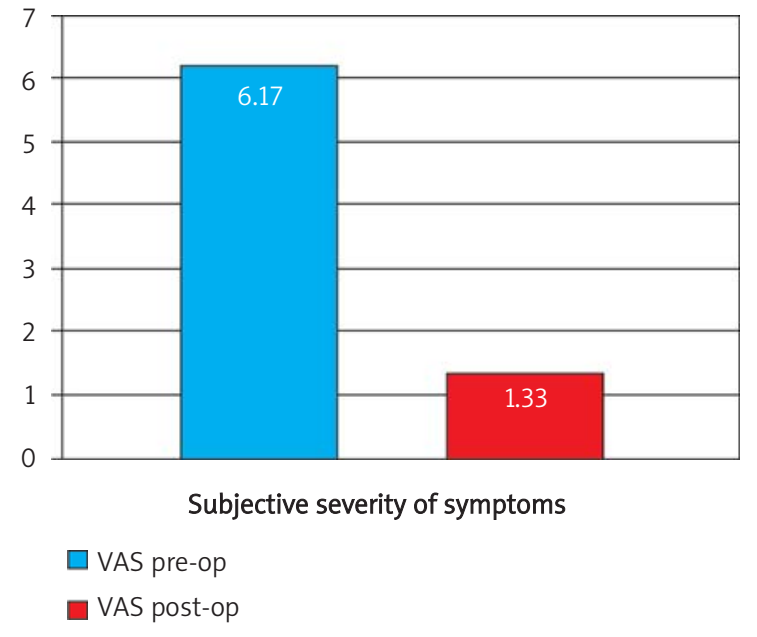

Figure 4. Subjective severity of symptoms prior to and 3 months after surgery $(p<0.05)$

patient. This problem arose from lack of an objective method of assessment of intraoperative efficacy of the procedure. Considering notions on continuous measurement of the skin temperature of lower limbs with a pyrometer, we plan to apply this method in all patients in the future to improve the efficacy of the procedure.
During the follow-up 3 months after the surgery, symptoms measured on the VAS scale seemed less intense and were reduced from $6.17 \pm 3.9$ to $1.33 \pm 0.58$ $(p=0.018$, Figure 4) and plantar sweating was also reduced from $8.75 \pm 2.56$ to $0.67 \pm 1.15$ ( $p=0.05$ ) with insignificantly reduced subjective sensation of compensatory hyperhidrosis. Subjective assessment of sweating in different body areas is shown in Table I.

The results of gravimetry, which is an objective form of evaluation of hyperhidrosis, are shown in Table II and Figure 5. The limit of the normal range of gravimetry is $40 \mathrm{mg}$ of sweat per minute. Patients were qualified for surgery with a result exceeding $100 \mathrm{mg} / \mathrm{min}$ and exclusion of secondary causes of hyperhidrosis [12]. Mean plantar sweating prior to surgery was $150 \pm 130 \mathrm{mg} / \mathrm{min}$ compared to $40 \pm 30$ $\mathrm{mg} / \mathrm{min}$ after the procedure.

In Figure 4 increased compensatory hyperhidrosis, described by Loureiro et al. [11], and occurring in similar procedures on the thoracic sympathetic trunk [12], can be noted. However, the small study group and preliminary nature of this publication call for further evaluation in a larger group of patients.

The cosmetic effect 3 months after surgery is shown in Figure 6. Due to the low number of patients,

Table I. Subjective assessment of hyperhidrosis in different body areas prior to and 3 months after lumbar sympathectomy (range 0-10)

\begin{tabular}{|lccc|}
\hline Location & Before surgery & 3 months after surgery & Statistical significance \\
\hline Facial & $1.50 \pm 2.35$ & $0 \pm 0$ & $\mathrm{~ns}$ \\
\hline Palmar & $1.08 \pm 2.61$ & $1.33 \pm 2.31$ & $p=0.37 \mathrm{~ns}$ \\
\hline Axillary & $2.92 \pm 3.26$ & $0 \pm 0$ & $p=0.09 \mathrm{~ns}$ \\
\hline Abdomino-lumbar & $3.17 \pm 2.86$ & $1.00 \pm 1.73$ & $p=0.21 \mathrm{~ns}$ \\
\hline Plantar & $8.75 \pm 2.56$ & $0.67 \pm 1.15$ & $p=0.05$ \\
\hline
\end{tabular}

Table II. Severity of hyperhidrosis in different body areas measured with gravimetry prior to and 3 months after surgery

\begin{tabular}{|lccc|}
\hline Location & Before surgery $[\mathrm{g} / \mathrm{min}]$ & 3 months after surgery $[\mathrm{g} / \mathrm{min}]$ & Statistical significance \\
\hline Facial & $0.02 \pm 0.01$ & $0.02 \pm 0.02$ & $p=0.40 \mathrm{~ns}$ \\
\hline Palmar & $0.05 \pm 0.07$ & $0.04 \pm 0.05$ & $p=0.09 \mathrm{~ns}$ \\
\hline Axillary & $0.05 \pm 0.07$ & $0.03 \pm 0.03$ & $p=0.23 \mathrm{~ns}$ \\
\hline Abdomino-lumbar & $0.03 \pm 0.02$ & $0.02 \pm 0.03$ & $p=0.25 \mathrm{~ns}$ \\
\hline Plantar & $0.15 \pm 0.13$ & $0.04 \pm 0.03$ & $p=0.13 \mathrm{~ns}$ \\
\hline
\end{tabular}




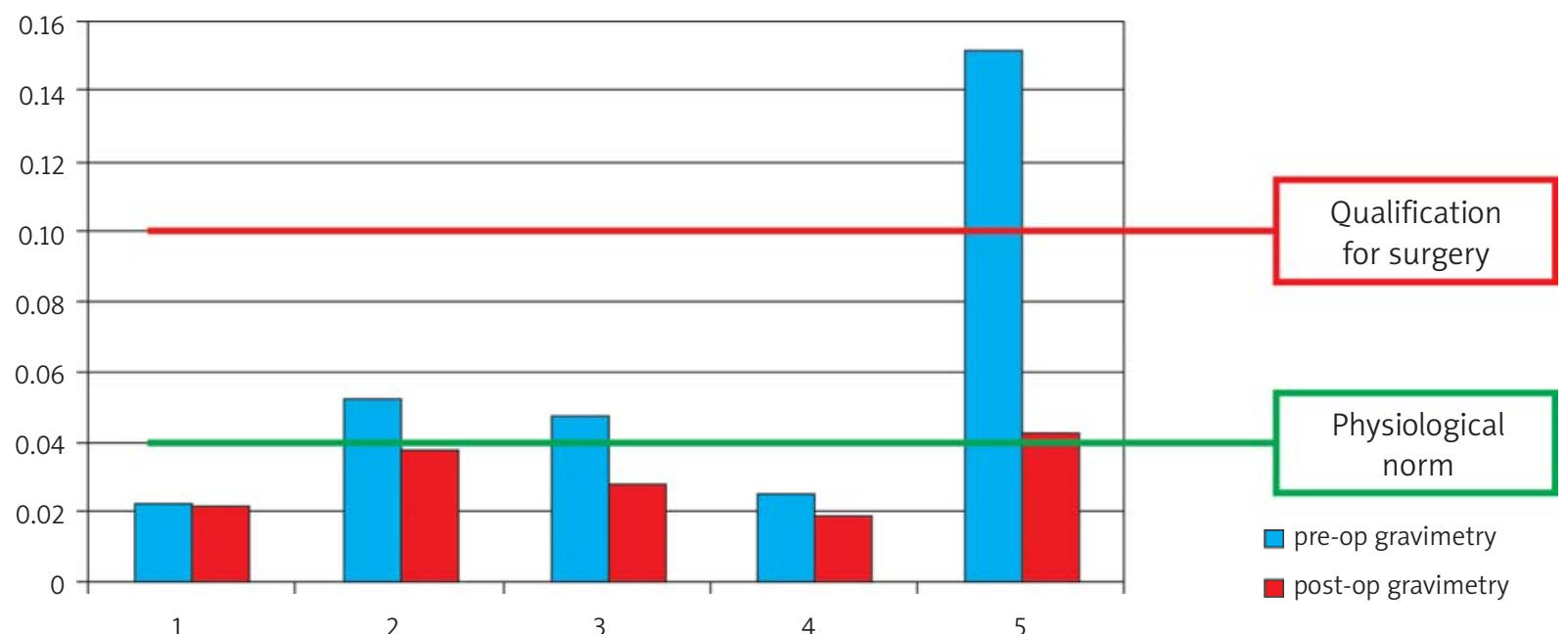

Figure 5. Severity of hyperhidrosis measured with gravimetry in different areas of the body prior to and 3 months after surgery

no analysis of the quality of life or assessment of cosmetic effects was performed. These studies will be performed soon and presented in another article.

\section{Discussion}

Lumbar sympathectomy is performed for numerous indications. In our centre primary hyperhidrosis is the most common one. In this paper we present the new procedure of videoretroperitoneoscopic lumbar sympathectomy from posterior access and its perioperative and early results of follow-up studies done at 3 months post-op. As one can see, this procedure is a valuable alternative to classical procedures with videoscopic assistance (for improved cosmetic effect) [27, 28], and for videoretroperitoneal procedures from lateral access (due to lesser risk of intraoperative lesion of the peritoneum) [29]. It should be mentioned that video-assisted procedures are applied in the treatment of vascular disease especially when the cosmetic effect is not a priority. The first video-assisted lumbar sympathectomy in Poland was performed by a team of Professor Wroński, who also broadened the knowledge of primary hyperhidrosis and its surgical treatment $[27,28]$.

Apart from hyperhidrosis, lumbar sympathectomy is performed for lower limb vascular diseases in patients who cannot have a revascularization procedure, for instance in Buerger's disease [13], Raynaud's sign [13], treatment of frostbite [30] and treatment of erection disturbances secondary to adrenergic hypotonia of corpora cavernosa [31]. Application of lumbar sympathectomy is of extreme significance in complex regional pain syndrome (CRPS) [10, 31]. According to the IASP (International Association for the Study of Pain) definition, since 1995 the term "CRPS" is used for causalgia, Sudeck's atrophy and reflex sympathetic dystrophy, i.e. nosological units characterised by burning pain, sympathetic hyperactivity in the affected region, skin hyperaesthesia, muscular dystrophy and joint stiffness. Complex regional pain syndrome can result from trauma, infection or surgery [10, 31], for instance laminectomy [8]. Complex regional pain syndrome is a syndrome of unknown pathomechanism, and hence

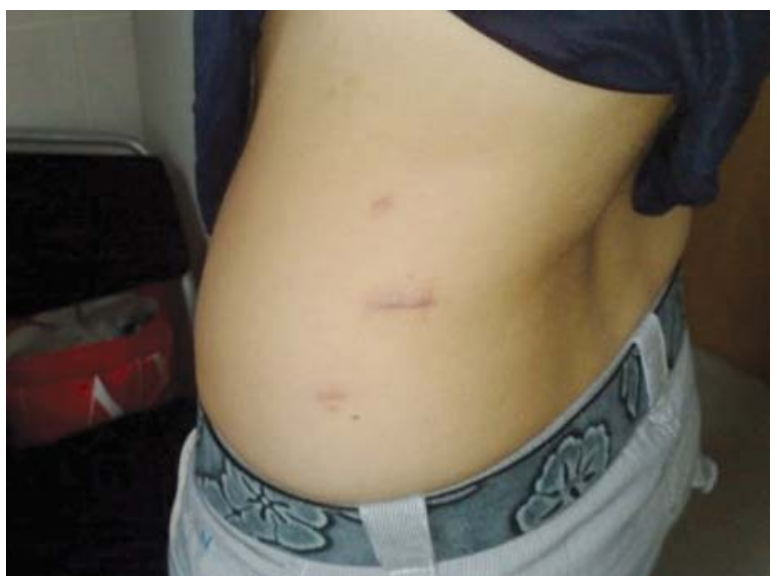

Figure 6. Cosmetic effect 3 months after surgery 
resistant to treatment $[10,31]$. Beneficial effects of lumbar sympathectomy with significant reduction of symptoms in $84 \%$ of patients [9] encourage broader application of this method, including the laparoscopic modification proposed herein.

Of course chemical sympathectomy with concentrated alcohol, phenol, or botulinum toxin A can be used for the aforementioned indications. These methods, however, have lesser efficacy and their effect is temporary; for instance, median duration of the therapeutic effect of botulinum toxin with bupivacaine was 71 days [33]. Repeated injections can cause post-puncture pain syndrome [22], and the need to perform the injection under CT guidance exposes a patient to ionizing radiation.

Another important issue is to find an objective intraoperative method for assessment of sympathectomy efficacy. Some authors recommend measurement of lower limb skin temperature [22, 34, 35], which should increase by approximately $1^{\circ} \mathrm{C}$ after cutting off the sympathetic impulse due to relaxation of the cutaneous vascular bed. Another useful parameter is electrical resistance of the skin [22].

\section{Conclusions}

The procedure of totally videoretroperitoneoscopic lumbar sympathectomy is an effective method of treatment for primary plantar hyperhidrosis, yet due to difficult and equivocal anatomical conditions in the retroperitoneal space it should only be performed in centres experienced in laparoscopic and videoscopic surgery of the retroperitoneal space.

\section{References}

1. Diez J. Um nuevo método de simpatectomía periférica para el tratamiento de las afecciones tróficas y gangrenosas de los miembros: la dissociación fascicular. Bol Soc Cir B Aires 1924; 8: 792.

2. Adson AW, Brown GE. Treatment of Raynaud's disease by lumbar ramisection and ganglionectomy and perivascular sympathectomy of the common iliacs. J Am Med Assoc 1925; 84: 1908-10.

3. Greenwood B. The origins of sympathectomy. Med Hist 1967; 11: 165-9.

4. Coventry BJ, Walsh JA. Cutaneous innervation in man before and after lumbar sympathectomy: evidence for interruption of both sensory and vasomotor nerve fibres. ANZ J Surg 2003; 73: 14-8.

5. Rogers JH, Laird JR. Overview of new technologies for lower extremity revascularization. Circulation 2007; 116: 2072-85.

6. Hernandoa FJ, Conejero AM. Peripheral artery disease: pathophysiology, diagnosis and treatment. Rev Esp Cardiol 2007; 60: 969-82.
7. Perez-Burkhardt JL, Gonzalez-Fajardo JA, Martin JF, et al. Lumbar sympathectomy as isolated technique for the treatment of lower limbs chronic ischemia. J Cardiovasc Surg 1999; 40: 7-13.

8. AbuRahma AF, Thaxton L, Robinson PA. Lumbar sympathectomy for causalgia secondary to lumbar laminectomy. Am J Surg 1996; 171: 423-6.

9. Bandyk DF, Johnson BL, Kirkpatrick AF, et al. Surgical sympathectomy for reflex sympathetic dystrophy syndromes. J Vasc Surg 2002; 35: 269-77.

10. Ghai B, Dureja GP. Complex regional pain syndrome: a review. J Postgrad Med 2004; 50: 300-7.

11. Loureiro MP, de Campos JR, Kauffman P, et al. Endoscopic lumbar sympathectomy for women: effect on compensatory sweat. Clinics (Sao Paulo) 2008; 63: 189-96.

12. Stefaniak T, Pirski MI, Osęka T, et al. Simultaneous bilateral transthoracic sympathectomy through posterior access in LinTelaranta modification for primary hyperhidrosis. Videosurgery and other miniinvasive techniques 2009; 4: 47-52.

13. Chander J, Singh L, Lal P, et al. Retroperitoneoscopic lumbar sympathectomy for buerger's disease: a novel technique. JSLS 2004; 8: 291-6.

14. Czyzewski D, Dobosz J, Wojtacha J, et al. Assessment of thoracic sympathectomy by transpleural posterolateral and thoracoscopic approach in surgical treatment of Raynaud's syndrome. Wiad Lek 2004; 57: 109-13.

15. Sanni A, Hamid A, Dunning J. Is sympathectomy of benefit in critical leg ischaemia not amenable to revascularisation? Interact Cardiovasc Thorac Surg 2005; 4: 478-83.

16. Bhattarai BK, Rahman TR, Biswas BK, et al. Fluoroscopy guided chemical lumbar sympathectomy for lower limb ischaemic ulcers. JNMA J Nepal Med Assoc 2006; 45: 295-9.

17. Taylor MS. Lumbar epidural sympathectomy for frostbite injuries of the feet. Mil Med 1999; 164: 566-7.

18. Giammusso B, Gattuso U, Vanaclocha V, et al. Percutaneous lumbar sympathectomy in the treatment of erectile dysfunction secondary to cavernous adrenergic hypertone: initial results of an original technique. Arch Ital Urol Androl 2005; 77: 5-9.

19. Drummond PD, Finch PM. Sympathetic nervous system involvement in the syndrome of painful legs and moving toes. Clin J Pain 2004; 20: 370-4.

20. Bannenberg J, Hourlay P, Meijer DW, Vangertruyden G. Retroperitoneal endoscopic lumbar sympathectomy: laboratory and clinical experience. Endosc Surg Allied Technol 1995; 3: 1620.

21. Bannenberg JJ, Hodde KC, Hourlay P, Meijer DW. Experimental retroperitoneal endoscopic surgery. Endosc Surg Allied Technol 1995; 3: 21-6.

22. Kathouda N, Wattanasirichaigoon S, Tang E, et al. Laparoscopic lumbar sympathectomy. Surg Endosc 1997; 11: 257-60.

23. Furlan AD, Mailis A, Papagapiou M. Are we paying a high price for surgical sympathectomy? A systematic literature review of late complications. J Pain 2000; 1: 245-57.

24. Leon-Sarmiento FE, Hernandez HG, Schroeder N. Abnormal tactile discrimination and somatosensory plasticity in familial primary hyperhidrosis. Neurosci Lett 2008; 441: 332-4. 
25. Schlereth T, Dieterich M, Birklein F. Hyperhidrosis - causes and treatment of enhanced sweating. Dtsch Arztebl Int 2009; 106: 32-7.

26. Weber A, Heger S, Sinkgraven R, et al. Psychosocial aspects of patients with focal hyperhidrosis. Marked reduction of social phobia, anxiety and depression and increased quality of life after treatment with botulinum toxin $\mathrm{A}$. Br J Dermatol 2005; 152: 342-5.

27. Wronski J. Lumbar sympathectomy performed by means of videoscopy. Cardiovasc Surg 1998; 6: 453-6.

28. Wronski J. Wideoskopowe metody odnerwienia współczulnego: własna metoda operacyjna sympatektomii lędźwiowej z użyciem wideoasysty. Rozprawa habilitacyjna. Akad Med, Lublin 2002.

29. Rieger R, Pedevilla S. Retroperitoneoscopic lumbar sympathectomy for the treatment of plantar hyperhidrosis: technique and preliminary findings. Surg Endosc 2007; 21: 129-35.

30. Taylor MS. Lumbar epidural sympathectomy for frostbite injuries of the feet. Mil Med 1999; 164: 566-7.

31. Giammusso B, Gattuso U, Vanaclocha V, et al. Percutaneous lumbar sympathectomy in the treatment of erectile dysfunction secondary to cavernous adrenergic hypertone: initial results of an original technique. Arch Ital Urol Androl 2005; 77: 5-9.

32. Rho RH, Brewer RP, Lamer TJ, Wilson PR. Complex regional pain syndrome. Mayo Clin Proc 2002; 77: 174-80.

33. Carroll I, Clark JD, Mackey S. Sympathetic block with botulinum toxin to treat complex regional pain syndrome. Ann Neurol 2009; 65: 348-51.

34. Frank SM, El-Rahmany HK, Tran KM, et al. Comparison of lower extremity cutaneous temperature changes in patients receiving lumbar sympathetic ganglion blocks versus epidural anesthesia. J Clin Anesth 2000; 12: 525-30.

35. Cooke ED, Harris J, Fleming CE, et al. Correlation of pain with temperature and blood-flow changes in the lower limb following chemical lumbar sympathectomy in reflex sympathetic dystrophy. A case report. Int Angiol 1995; 14: 226-8. 